\title{
O DOCUMENTÁRIO: UM GÊNERO DISCURSIVO NO ENSINO DE LÍNGUA PORTUGUESA
}

\author{
Maraisa Daiana da Silva \\ Doutoranda em Letras pela Universidade Estadual de Maringá. \\ maraisa.d.silva@gmail.com
}

\section{RESUMO}

O ensino de Língua Portuguesa se fundamenta na concepção de linguagem como interação social e tem por objetivo levar para o ambiente escolar as diferentes linguagens que se constituem nas mais diversas situações de interação. Compreende-se, então, que a língua se estabelece nas diferentes esferas de comunicação por meio dos gêneros discursivos, conforme as teorias bakhtinianas. Nessa direção, este artigo busca refletir, teoricamente, sobre o documentário como gênero discursivo, o qual pode contribuir para o ensino de Língua Portuguesa. Dessa forma, ancorado pelo círculo de Bakhtin, este artigo parte da definição de gêneros discursivos, transita pelas teorias do cinema, mais especificamente do documentário, objetivando apresentá-lo como um gênero discursivo, para, por fim, discutir suas potencialidades no ensino. A partir do levantamento bibliográfico realizado, considera-se que o gênero documentário, como gênero segundo, possibilita a prática pedagógica, no processo de ensinoaprendizagem de Língua Portuguesa, viabilizando ao aluno estabelecer relações entre língua, cultura, arte, história e realidade.

Palavras-chave: Cinema; Ensino; Bakhtin.

\section{RESUMÉ}

L'enseignement de la langue portugaise repose sur la conception de la langue en tant qu'interaction sociale et vise à apporter au milieu scolaire les différentes langues constituant les situations d'interaction les plus diverses. On comprend alors que le langage se constitue dans les différentes sphères de la communication à travers les genres discursifs, selon les théories bakhtiniennes. Par conséquent, cet article cherche à réfléchir, théoriquement, sur le documentaire comme genre discursif, ce qui peut contribuer à l'enseignement de la langue portugaise. Ainsi, ancré par Bakhtine, cet article part de la définition des genres discursifs, retransmet les théories du cinéma, plus spécifiquement du documentaire, dans le but de le présenter comme un genre discursif, pour enfin discuter de ses potentialités en enseignement. D'après l'enquête bibliographique, il est considéré que le genre documentaire, en tant que deuxième genre, permet la pratique pédagogique dans le processus d'enseignement-apprentissage de la "langue portugaise», permettre à l'étudiant d'établir des relations entre langue, culture, art, histoire et réalité.

Mots-clés: Cinéma, Enseignement, Bakhtin. 


\section{INTRODUÇÃO}

A imagem é parte essencial para a formação do ser humano, e é por meio delas que se conhecem seres humanos, comunidades, culturas, ideologias, etc. Aliadas ao som e aos enunciados, as imagens, quando em movimento, se transformam em impressionantes recursos de imersão e de ensino. Desse modo, criado há pouco mais de um século, o cinema tem se revelado importante dispositivo técnico e tecnológico.

Localizado em uma época e um espaço, o cinema cria condições para a coexistência enunciativa que se delineia, inicialmente, no âmbito da formação dos conceitos. De modo que se torna um espaço de circulação de diferentes enunciados que reverberam verdades de uma época; de espaços cujas limitações têm, no corpo biológico, sociocultural e político, a superfície de sua inscrição material e discursiva.

Por ser um dispositivo maquínico, técnico e tecnológico, o cinema se organiza sob uma urgência enunciativa, narra, descreve e interpreta acontecimentos. Nessa direção, destaca-se o documentário, que é capaz de se articular a diferentes temas e se mostra apto de ser empregado na prática docente para tornar o processo de ensinoaprendizagem significativo.

Levando em consideração a definição de gênero discursivo - uma unidade de ensino, pensando na leitura, tal qual na produção - é essencial trabalhar os gêneros do discurso, quando o ensino se volta para os textos, tendo como subsídio seu aspecto temático, composicional e estilístico.

Diante disso, este trabalho tem por objetivo refletir, teoricamente, sobre o documentário como gênero discursivo, o qual pode contribuir para o ensino de Língua Portuguesa. Para tanto, esta reflexão baseia-se em levantamento bibliográfico, possui 
caráter exploratório e se propõe a realizar um debate sobre a temática. Assim, subsidiado pelo Círculo de Bakhtin, este artigo parte de aportes teóricos que definem os gêneros discursivos, perpassando pelas teorias do cinema, mais especificamente do documentário, para, por fim, discutir suas potencialidades no ensino.

\section{Gênero discursivo: definições}

O ensino de Língua Portuguesa se fundamenta na concepção de linguagem como interação social e deve possibilitar aos alunos experiências que ampliem os letramentos “[...] de forma a possibilitar a participação significativa e crítica nas diversas práticas sociais permeadas/constituídas pela oralidade, ela escrita e por outras linguagens." (BRASIL, 2017, p. 67). Defende-se, então, que a língua se constitui nas diferentes esferas de comunicação, por meio dos gêneros discursivos, conforme as teorias bakhtinianas.

Ao reconhecer que os gêneros têm uma riqueza imensa, devido a sua grandiosidade, compreende-se que não é uma tarefa fácil, muito menos de pouca relevância, selecioná-los e empregá-los em sala de aula, visando atender as necessidades dos alunos e construir uma sociedade letrada e crítica. Mas o que são os gêneros discursivos? Como se caracterizam?

Mari, ao discutir sobre gênero, reitera que "Ainda estão longe de representar padrões de categorização rigorosos, ou mesmo explicações teóricas razoáveis para tudo aquilo que constitui nossa atividade de linguagem numa sociedade, se a eles pretendemos atribuir essa abrangência" (2004, p. 65).

As diversas esferas da atividade humana estão, sem exceção, intimamente ligadas à utilização da língua. Isto é, a comunicação, seja ela falada ou escrita, está ligada ao 
gênero do discurso, os quais são os responsáveis por organizar essa interação. Nessa

perspectiva, Swales (1990) afirma que:

\begin{abstract}
Um gênero compreende uma classe de eventos comunicativos cujos exemplares compartilham os mesmos propósitos comunicativos. Esses propósitos são reconhecidos pelos membros mais experientes da comunidade discursiva original e constituem a razão do gênero. A razão subjancente dá o contorno da estrutura esquemática do discurso e influencia e restringe as escolhas de conteúdo e estilo. O propósito comunicativo é o critério que é privilegiado e que faz com que o escopo do gênero se mantenha enfocado estreitamente em determinada ação retórica compatível com o gênero. Além do propósito, os exemplares do gênero demonstram padrões semelhantes, mas com variações em termos de estrutura, estilo, conteúdo e público-alvo. Se forem realizadas todas as expectativas em relação àquilo que é altamente provável para o gênero, o exemplar será visto pela comunidade discursiva original como um protótipo. (SWALES, 1990, p. 58)
\end{abstract}

Para Bakhtin (2003), o sujeito pode até não perceber a existência teórica dos

gêneros discursivos, mas os utiliza com total segurança, transita pelas mais diversas esferas, tendo um repertório infinito de gêneros ao seu dispor; faz as transformações necessárias sem se intimidar, o que pode dar ao gênero a aparência de algo sem delimitações. Esses gêneros são usados em comunicações tanto informais quanto formais, entendidos pelo autor como gêneros primários e gêneros secundários, respectivamente.

De acordo com Bakhtin,

[...] falamos apenas através de determinados gêneros do discurso, isto é, todos os nossos enunciados possuem formas relativamente estáveis e típicas de construção do todo. Dispomos de um rico repertório de gêneros do discurso orais (e escritos). Em termos práticos, nós os empregamos de forma segura e habilidosa, mas em termos teóricos podemos desconhecer inteiramente sua existência. [...] até mesmo no bate-papo mais descontraído e livre nos moldamos nosso discurso por determinadas formas de gênero, às vezes padronizadas e estereotipadas, às vezes mais flexíveis, plásticas e criativas [...]. Esses gêneros do discurso "nos são dados quase da mesma forma que nos é dada a língua materna, a qual dominamos livremente até começarmos o estudo da gramática". (BAKHTIN, 2003, p. 282-83) 
O círculo define os gêneros como "formas relativamente estáveis e normativas de enunciado" (BAKHTIN, 2003, p. 286). Desse modo, entende-se que esses gêneros, ao mesmo tempo que são estáveis, também são volúveis e estão em contínua transformação, apesar de suas características cristalizadas. É a demanda de uma determinada esfera, a necessidade de se comunicar bem, segundo a instância que o sujeito está inserido, que vai fazer com que os gêneros se modifiquem ou até mesmo que produzam novos gêneros.

Tudo isso é acionado quando a língua é colocada em uso, o que se concretiza por meio do enunciado. Esses tipos relativamente estáveis são determinados sócioshistoricamente, elaborados e adaptados conforme a instância de utilização. Sobral, ao explicar a possibilidade de algo ser normativo e ao mesmo tempo estável, afirma que

[...] essas formas e tipos são sim normativos, dado que o ambiente sóciohistórico requer a cristalização de formas (e mesmo de fórmulas) para que não se tenha de "reinventar" a cada vez que se fala os modos de falar. Mas como ocorre no nível dos enunciados e, portanto, no âmbito da comunicação discursiva, essa normatividade é mutável. (SOBRAL, 2009, p. 116)

Depreende-se, então, que os gêneros são delineados por tipos mais ou menos estáveis de enunciados. Sendo que, estes enunciados possuem uma organização própria e uma marca concreta, buscam tipos de textualização relativamente estável, não completamente, contudo, que possibilitem adequações e transformações. Assim, ao entender que existem infinitas situações comunicativas, pode-se afirmar que existem infinitos gêneros discursivos, o que é confirmado por Bakhtin:

A riqueza e a diversidade dos gêneros discursivos são ilimitadas, porque as possibilidades de atividade humana são também inesgotáveis e porque cada esfera de atividade contém um repertório inteiro de gêneros discursivos que se 
diferenciam e se ampliam na mesma proporção que cada esfera particular se desenvolve e se torna cada vez mais complexa. (BAKHTIN, 1986, p. 60)

Desse modo, entende-se que os gêneros vão sofrendo alterações conforme o momento sócio-histórico em que estão inseridos, de acordo com a época e sua emergência. Diante disso, cada situação social particular gera gêneros novos, com características próprias, ou seja, tudo depende das condições de produção, da demanda das novas esferas que vão surgindo ou que se transformam para suprir uma determinada exigência social.

Evidencia-se que é a experiência, nas mais diferentes situações comunicativas, que assegurará o contato com os mais diversos gêneros, além de auxiliar na competência linguística do gerador de enunciados.

Bakhtin (2003), como já mencionado, diferencia os gêneros primários, que são os tipos utilizados na comunicação cotidiana, dos gêneros secundários, que são utilizados em construções mais elaboradas. Os gêneros secundários têm formas complexas por serem elaborados a partir de uma comunicação cultural organizada, como a política, a arte, entre outros. Assim, diferenciar os gêneros é entender o uso da linguagem enquanto um processo dialógico, em que há interação, o que não quer dizer que esses gêneros não podem estar presentes um no outro. Segundo Machado "[...] nada impede, portanto, que uma forma do mundo cotidiano possa entrar para a esfera da ciência, da arte da filosofia, por exemplo" (2005, p. 155).

O documentário se encaixa nessa perspectiva de modo singular, visto que é capaz de levar para a sala de aula o corriqueiro de maneira a ser pensado e analisado, através de um terceiro ponto de vista, do documentarista, que transforma o cotidiano em arte. 
A partir desse excerto, a discussão aqui exposta busca, na sequência, discorrer sobre o documentário e, mais especificamente, refletir sobre seu emprego como um gênero discursivo e suas possibilidades no ensino.

\section{Elementos do documentário: algumas características}

O documentário nunca teve uma definição precisa. John Grierson, em 1930, afirmou que consistia em um tratamento criativo da realidade, além de trazer a inquietação causada pelos termos "tratamento criativo" e "realidade". O primeiro termo insinuava a liberdade artística de criar, enquanto o segundo, realidade, suscitava a seriedade dos jornalistas, por exemplo. Nichols (2016) vai sugerir que nem um nem outro é predominante, mas que no novo cinema esses dois aspectos se equilibram. A criatividade, respeitando o mundo histórico, é o que o documentário executa, assim, "nem invenção ficcional nem reprodução fatual, o documentário recorre à realidade histórica e a ela se refere ao representá-la de uma perspectiva diferente" (NICHOLS, 2016, p. 30).

Dessa maneira, o documentário está fadado a representar o que é visível no presente, enquanto que compete à ficção representar o invisível, o hipotético, e também o passado, pois sem atores é impossível reconstituir uma história. Nessa direção, Rotha (1968) salienta que "acima de tudo, o documentário deve refletir os problemas e as realidades do presente. Ele não pode chorar sobre o passado; e lhe é perigoso anunciar o futuro" (ROTHA apud GAUTHIER, 2011, p. 14).

Desse modo, o que define "se um filme pertence ou não ao gênero documentário são as interações sociais entre as partes envolvidas no processo de produção/recepção dos discursos" (MEDEIROS; GOMES, 2014, p. 165). É essa definição que nos remete aos 
processos interacionais apontados pelo círculo de Bakhtin. Essa interação, segundo Nichols, é feita "com diferentes pressupostos em relação à finalidade, envolvem uma relação diferente entre o cineasta e o assunto e provocam diferentes tipos de expectativas" (NICHOLS, 2016, p. xi).

Nichols (2016) afirma, ainda, que a definição de documentário deve ser abordada a partir de quatro ângulos: o das instituições, o dos profissionais, o dos textos e o da audiência. O Quadro 1, a seguir, exemplifica esses ângulos.

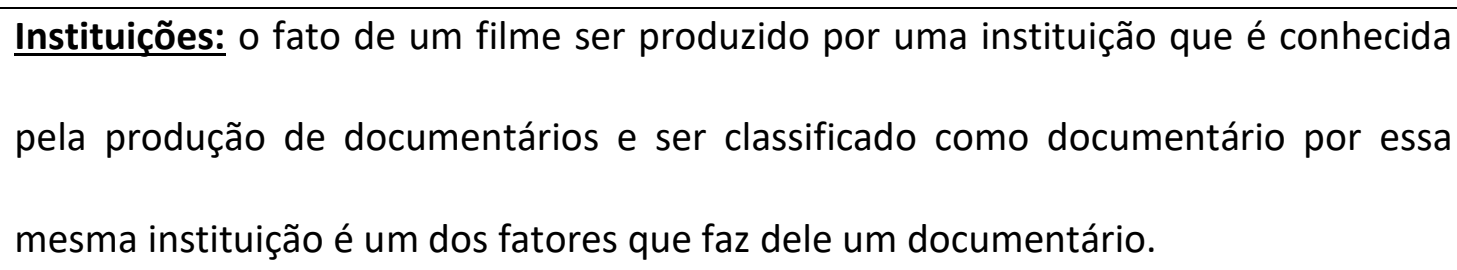

Audiência: a noção de que um filme é um documentário é construída pela mente do observador tanto quanto é construída por seu contexto e estrutura.

Profissionais: os profissionais do ramo do documentário falam uma mesma língua, compartilham uma espécie de mandato para representar o mundo histórico ao invés de inventar mundos alternativos, fazendo com que compartilhem um senso de propósito, apesar das diferenças de estilos e técnicas.

Textos: convenções textuais também ajudam a reconhecer um filme enquanto documentário. A técnica do comentário em voz over, as entrevistas, as locações, a presença de atores sociais ou pessoas em suas atividades cotidianas são características comuns a vários documentários, apesar de não serem condição sine qua non.

Quadro 1 - Os quatro ângulos que definem documentário, de acordo com Nichols Fonte: Adaptado de Medeiros e Gomes (2014, p. 166-167). 
O documentário leva um novo olhar do mundo e dos acontecimentos, narrativas que vão além dos horizontes limitados e criam novas possibilidades. É, também, o responsável por lançar um cinema de envolvimento social e visão pessoal e crítica, o que o fez se propagar pela internet, sites e redes sociais.

Por trazerem os fatos reais, os documentários narram o que conduz a acontecimentos ou até mesmo a modificações reais que envolvem um indivíduo ou toda uma comunidade. Nessa direção, segundo Nichols (2016), trazem uma confissão de como as coisas são, como mudam e quem produziu essa mudança.

Nessa direção, o olhar do documentarista para o objeto marca, de forma incontestável, o documentário. Ele não tem a obrigação de disfarçar ou esconder sua subjetividade sobre o objeto narrado. O diretor tem um privilégio do qual o repórter não pode gozar, visto que não deve ser julgado como parcial ou até mesmo manipulador de uma determinada notícia, ainda que isso possa acontecer. O autor de um documentário tem a liberdade de opinar, se colocar, expor seu ponto de vista e manipular o que está sendo exposto, sem ter a necessidade de mascarar suas ideias frente ao telespectador. Diante disso, Salles (2001) argumenta que:

\footnotetext{
Um documentário ou é autoral ou não é nada. [...] A autoria é uma construção singular da realidade. Logo, é uma visão que me interessa porque nunca será a minha. E exatamente isso que espero de qualquer bom documentário: não apenas fatos, mas o acesso a outra maneira de ver. (SALLES apud MELO, 2002, p. 30)
}

Com certa facilidade, é possível ir de encontro à asserção de que o documentário é pessoal e que é extremamente necessário que o diretor exponha seu ponto de vista sobre o fato narrado. Corroborando essa ideia, Melo afirma que "a subjetividade e a ideologia estão fortemente presentes na narrativa do documentário, oferecendo 
representações em forma de texto verbal, sons e imagens. É impossível ao documentarista apagar-se" (2002, p. 30). O autor defende, ainda, que a polifonia no documentário também busca assinalar o ponto de vista do diretor. Dessa maneira, a costura de vozes direciona o telespectador a um entendimento claro de qual é o posicionamento do documentarista sobre o tema retratado.

No documentário, é sabido que só partindo de outros lugares, de outras vozes é que vai conseguir se constituir. Diante disso, o autor recorre a fontes diversas para trazer contribuições, as quais podem ser buscadas em arquivos e documentos ou, ainda, em conversas simples com testemunhas do fato em apuração.

Quando recorre a testemunhas, o documentarista deve estar atento e buscar não só uma testemunha, mas sim um número expressivo que confirme uma tese ou ainda que a confronte. Logo, as entrevistas são fontes de informação para a construção da narração, sendo que elas podem integrar ou não o documentário.

O que diferencia o documentário do real é a edição. Com cortes e montagens, é possível criar uma linha narrativa em que não se pode contestar a influência do diretor. Essa edição é que vai determinar o caminho para a defesa de uma ideia, consolidar um discurso ou, até mesmo, omitir ou fantasiar.

Nessa perspectiva, ao falar do gênero documentário não se pode delimitá-lo em uma forma fixa, partindo de enunciados típicos, ou mesmo partindo de tipos textuais como narração, descrição, entre outros. Porém, não restam dúvidas que o documentário é um gênero com traços particulares, traços que o constituem e fazem com que o sujeito o reconheça como tal, assim, existe uma certa regularidade que o determina.

À vista disso, é possível depreender que os documentários são capazes de trazer para um ambiente, educacional ou não, debates, demarcando espaços de discussões, 
construindo e também desconstruindo olhares formados. Têm uma abrangência de objetos, o que autoriza este gênero cinematográfico a se aproximar e se encaixar nos conteúdos escolares.

\section{Documentário: um gênero discursivo}

Segundo Bakhtin (1997 apud MEDEIROS; GOMES, 2014, p. 161), os gêneros surgem a partir de novas necessidades comunicativas do homem, o que faz com que estejam essencialmente ligados a um contexto sócio-histórico e cultural. Isso significa que o gênero "está inserido na cultura, em relação a qual se manifesta como 'memória criativa' onde estão depositadas não só as grandes conquistas das civilizações, como também as descobertas significativas sobre os homens e suas ações no tempo e no espaço" (MACHADO, 2005, p. 159).

Bakhtin (2003) aponta que sua teoria pode ser aplicada aos gêneros escritos e falados, porém, ao considerar que a ciência evolui e ao partir da teoria do próprio autor, é possível aplicá-la também aos gêneros audiovisuais. À vista disso, considera-se o documentário enquanto gênero discursivo secundário, pois faz parte do cinema enquanto arte e, ao mesmo tempo, em sua composição, faz uso de diálogos da esfera do cotidiano e os transforma em um produto verbal mais aprimorado.

Sobre sua trajetória, o reconhecimento do documentário enquanto um gênero desassociado da ficção aconteceu no final dos anos 1920 e início dos anos 1930. No Brasil, apenas na década de 1960 surgiu o cinema documental que apresentava uma maior identidade nacional. Com o passar do tempo esse gênero se desenvolveu e começou a apresentar novos e heterogêneos contornos, conforme os diretores testavam novos formatos: 


\begin{abstract}
Tal heterogeneidade faz com que seja difícil responder o que caracteriza o documentário enquanto gênero, uma vez que não podemos reclamar para o documentário o status de reprodutor da realidade (o que o distanciaria da fiç̧ão, que antes de realidade seria imaginação, tornando a equação bastante simples. Mas não é dessa forma que o documentário deve ser encarado). É fato que o documentário aborda o mundo em que vivemos antes de um mundo imaginado pelo diretor, no entanto, ele não é a réplica ou cópia de algo que já existe, mas sim uma representação do mundo que nós já ocupamos, e tal representação é construída a partir de um ponto de vista entre vários outros possíveis (Nichols, 2001). (MEDEIROS; GOMES, 2014, p. 164)
\end{abstract}

Entretanto, de acordo com Medeiros e Gomes (2014), existe uma recorrência de elementos apresentados no documentário que fazem com que permitam que seja considerado um gênero. Antes o rap e o hip hop eram os porta-vozes de uma significativa parcela dos setores que estão à margem (HERSCHMANN, 2000), agora, junto a eles, está o audiovisual, que vem ganhando cada vez mais espaço. O documentário é um desses gêneros discursivos que promove isso, traz, através da arte, como gênero secundário, o cotidiano e, muitas vezes, vozes silenciadas. Vozes que apresentam um mundo distante e ao mesmo tempo presente nas vidas dos alunos, que tantas vezes tem um ponto de vista estereotipado, devido a limitação de informação.

Nessa perspectiva, compreende-se que era, há certo tempo atrás, indispensável apenas saber ler e escrever. Na contemporaneidade é necessário ir além, é preciso conhecer o potencial de uma imagem, saber decodificar e saber usá-la. Atualmente, as periferias não precisam mais exclusivamente da mídia televisiva para mostrar suas ideias e cultura. De acordo com Vianna (2007, s/p), em seu Manifesto, "as periferias das cidades inventam com velocidade impressionante novos circuitos culturais, e novas soluções econômicas - por mais precárias ou informais que sejam - para dar sustentabilidade para essas invenções". 
O cinema, na atualidade, está abrangendo uma produção gigantesca de temáticas diversificadas, incluindo as que estão à margem, e narrativas heterogêneas, que contribuem para que também se tenha uma heterogeneidade de olhares, pontos de vista diferentes sobre a mesma questão. Tudo isso pede um olhar peculiar, antes de se admitir o surgimento de um novo gênero audiovisual, com toda a autonomia e características provenientes dessa modalidade.

Foi no romance que Bakhtin observou a presença tanto dos gêneros primários como dos secundários em um mesmo produto, identificando a presença das diversas linguagens. Nessa direção, é a heterogeneidade dos gêneros discursivos que possibilita que um enunciado corrobore para a formação de outro e outro, sucessivamente. Essas observações podem ser levadas, também, para o contexto televisivo, para o cinema, para as tecnologias da comunicação, como já explicitado.

Não é o bastante afirmar que um documentário é um gênero discursivo. É necessário discuti-lo como uma potencialidade híbrida dos gêneros discursivos, para que, assim, seja possível entender o que essa infinidade de imagens, sons e cores pode desencadear e, por conseguinte, contribuir no processo de ensino-aprendizagem de língua portuguesa como gênero, reflexão que se apresenta a seguir.

\section{Abordagem do gênero discursivo documentário no ensino}

Os gêneros e as atividades são inerentes entre si, pois o agir de um sujeito não está livre da interação, nem mesmo a comunicação independe do agir, segundo Faraco (2003). Desse modo, as pessoas se comunicam e agem a partir dos gêneros, e o discurso é moldado pelas práticas de linguagem, pelo agir humano e pelas atividades que exercem. O teórico segue defendendo que Bakhtin se detém à linguagem, 
compreendendo que essa não é um sistema de classes gramaticais abstratas, mas sim algo concreto em constante transformação. Assim, não é possível delimitar a linguagem como elemento gramatical homogêneo, mas como algo sedimentar, que se define a partir das diversas vozes que caracterizam a linguagem.

A investigação, partindo dos pressupostos bakhtinianos, é de extrema importância para entender o ser como heterogêneo, participante ativo das infinitas comunicações sociais e participante de uma realidade que se amplifica, pela guerra das vozes sociais, como diz Bakhtin. Os indivíduos produzem seus enunciados através dos diferentes gêneros e esses retratam as intenções comunicativas dos falantes, quando o indivíduo produz um enunciado e o faz com uma certa finalidade, segundo o contexto em que está inserido. Portanto, a língua(guem) deve ser entendida sempre considerando o dizer e o ato do ser.

Cogitar o ensino de língua, por conseguinte, o trabalho com o texto, é cogitar uma abordagem em que a perspectiva seja sócio-histórica. Isso porque não deve se delimitar as formas e estrutura da língua isolada do contexto social em que o enunciado está inserido, nem mesmo considerar os gêneros como classes e tipos, como é entendido por outros estudos. Assim, é preciso considerar a esfera de funcionamento em que o gênero mobiliza o texto a ser trabalhado, além de olhar para o extraverbal e para o verbal, para o linguístico e extralinguístico. Não se deve, a partir do círculo de Bakhtin, desassociar essas duas dimensões.

Nessa perspectiva, vale ressaltar que texto, para o Círculo, é o espaço em que as escolhas dos recursos linguísticos e estilísticos acontecem. O texto, desse modo, é a totalidade do sistema de signos, na qual a capacidade de compreensão do indivíduo sustenta a coerência e unidade do ato comunicativo. Nas palavras de Barros "o texto [...] 
tal como Bakhtin o entende: tecido polifonicamente por fios dialógicos de vozes que polemizam entre si, se completam ou respondem umas às outras" (BARROS, 1999, p. 4).

O processo de ensino-aprendizagem atravessa a compreensão do lugar históricosocial em que esses processos acontecem e se modificam, conforme novas exigências são postas ao domínio da sala de aula. Sendo assim, no atual contexto, as novas demandas e transformações pedem novas articulações entre formas didático-pedagógicas de ensino, que já estavam tradicionalmente estabilizadas, e outras formas de linguagem em sala de aula. É nesse contexto e com base nessas necessidades que o documentário surge como ferramenta, como já explicitado, que pode corroborar para a formação e o letramento do aluno.

Diante disso, é importante ressaltar que as práticas de letramento são culturalmente construídas. Portanto, consistem em fenômenos dinâmicos e mutáveis por estarem inseridas na vida e na sociedade (STREET, 2003). Segundo Rojo (2001, p. 237), o modelo autônomo de letramento prevê um efeito "civilizatório", de caráter individual, cognitivo e social sob uma perspectiva tecnológica de progresso e de mobilidade social.

De acordo com Gonçalves (2012), a maneira como a escola compreende o letramento retrata um indício de como a sociedade recebe as outras formas de letramento, porque ela é, nesse aspecto, uma instituição que possui poder para autorizar ou não o reconhecimento desses outros letramentos.

Dessa maneira, o documentário, por meio de sua heterogeneidade de materiais, com a polifonia, ou seja, as várias vozes que estão marcadas, tanto nos depoimentos como nas imagens, além do ponto de vista do documentarista, suscitam a reflexão sobre o espaço do documentário na sala de aula. É um gênero rico, capaz de contribuir para o letramento, visto que são capazes de trazer uma infinidade de percepções, olhares 
diversos do cotidiano, em que a estética é o alicerce, tendo, por exemplo, a política como tema no discurso.

Ao compreender o documentário como gênero secundário no processo de ensinoaprendizagem, como apresentado neste estudo, é preciso que o docente, a partir de uma perspectiva dialógica, entenda o objeto. Assim, é necessário compreender o documentário que será estudado (as características, pontos discutíveis, entre outros) e problematizar as várias vozes para, então, desconstruir sua estrutura e, posteriormente, realizar um levantamento dos temas retratados pelo gênero, com a acuidade de não o tratar como um modelo ou ideia pronta independente.

À vista disso, ao trabalhar com o gênero documentário, o docente vai além, pois é preciso, para a leitura de imagens, nesse caso contidas no documentário, "além da habilidade de ler e escrever, o indivíduo deve possuir a habilidade de utilizar a informação visual, buscando integrar os significados que esta informação fornece" (SILVINO, 2014, $\mathrm{s} / \mathrm{p})$. Porém, não se trata apenas da capacidade/habilidade de ler e interpretar as imagens, mas também relacionar a imagem com o seu contexto social, histórico e cultural.

É importante lembrar que, ao adotar um gênero com imagens em movimento, o professor estará também contribuindo para a aprendizagem do vocabulário de língua portuguesa. De acordo com Souza (2009 apud Silvino, 2014), quando o indivíduo analisa essas imagens, ele deve ser capaz também de organizar, construir sentido e expressar o que foi compreendido, por exemplo, através de gêneros primários, como uma discussão entre alunos e professor. 
Nesse sentido, o gênero documentário, como gênero segundo, possibilita a prática docente, no componente curricular língua portuguesa, para que esse permita ao aluno estabelecer relações entre língua, cultura, arte, história e realidade.

Assim, o documentário, ao apresentar os fatos reais, possibilita ao professor ir muito além do simples alfabetizar, ao trabalhar, por vezes, com questões delicadas, porém, partindo de um gênero complexo, que impulsiona de forma onisciente a discução da realidade de seus próprios alunos. Dessa maneira, o docente permite que os discentes olhem para além do que está impresso, que reflitam sobre a suas próprias vivências, bem como do outro, e que tenham uma conduta cidadã ética e moral.

\section{Considerações finais}

A partir das características apresentadas acima, é possível compreender o documentário como gênero secundário do discurso, ou seja, um gênero complexo que toma os gêneros primários para si e os transformam. Nessa direção, os gêneros primários e os gêneros secundários não podem ser considerados enunciados separadamente, mas sim um componente do enunciado, em que, juntos, se ressignificam para constituir um único enunciado. Isto posto, é possível afirmar que um documentário não é constituído por um emaranhado de opiniões de testemunhas, mas sim um enunciado ímpar, já que deve ser marcado pelo instante em que se dá voz ao outro, segundo a definição bakhtiniana.

O obstáculo encontrado diante de uma análise audiovisual pode estar exatamente nesse ponto, na necessidade de fragmentá-lo para analisar, desconsiderando, dessa maneira, a dimensão do enunciado. É preciso centralizar a análise no gênero como um 
todo, partindo da significação integral do enunciado, considerando a sua multimodalidade.

Nesse contexto, infere-se que o documentário é capaz de se articular com diferentes temas, apresenta uma narrativa que abarca outras possibilidades artísticas, seja pelo figurino, pela cenografia, pela fotografia e por meio do diálogo entre a imagem e o mundo extra fílmico. Conjunto que favorece, na prática de sala de aula, para o componente curricular "Língua Portuguesa", ao estabelecer relações entre língua, cultura, arte e história. Dessa maneira, permite também a abordagem de temáticas que demandam condutas éticas e educativas na sociedade contemporânea, especialmente no que tange ao letramento visual e social.

Diante disso, evidencia-se que o cinema e, mais especificamente, o documentário, mostram-se como possibilidade para atingir o letramento, dada sua atualidade e urgência. Por fim ressalta-se que o emprego do documentário, em sala de aula, como gênero secundário, ainda que requeira, do professor, domínio de suas bases para seu uso, apresenta-se como uma importante ferramenta para a prática pedagógica.

\section{Referências}

BAKHTIN, M. Estética da Criação verbal. Trad. Paulo Bezerra, São Paulo: Martins Fontes, 2003.

BAKHTIN, M. Speech Genres \& Other Late Essays. Austin: University of Texas, 1986.

BARROS, D. L. P. Dialogismo, polifonia e enunciação. In: BARROS, D. L. P.; FIORIN, J. L. (Orgs.) Dialogismo, polifonia, intertextualidade. São Paulo, SP: Edusp, 1999.

BRASIL. Base Nacional Comum Curricular. Brasília: MEC, 2017.

FARACO, C. A. Linguagem e diálogo: as idéias do círculo de Bakhtin. Curitiba: Criar edições, 2003. 
GAUTHIER, G. O documentário: um outro cinema. Trad. Eloisa Araújo Ribeiro. Campinas, SP: Papirus, 2011.

GONÇALVES, R. F. C. R. Cidadania, Inclusão e Biopolítica: a identidade linguística em contradição no processo seletivo Vestibular dos Povos Indígenas no Paraná, 2012.

Dissertação (Mestrado)-Programa de Pós-Graduação em Letras da Universidade Estadual de Maringá, Maringá, 2012.

HERSCHMANN, M. O funk e o hip-hop invadem a cena. Rio de Janeiro: Editora UFRJ, 2000.

MACHADO, I. Gêneros discursivos. In: BRAIT, B. (org). Bakhtin: Conceitos Chaves. São Paulo; Contexto, 2005, p. $151-165$.

MARI, H. Sobre a importância dos gêneros discursivos. In: MACHADO, I.; MELL, R. Gêneros: reflexões em análise do Discurso. Belo Horizonte: NAD, 2004.

MEDEIROS, P.; GOMES, I. M. A. M. Gênero e Dialogismo: um olhar sobre o documentário ambiental a partir de mikhail bakhtin e bill nichols. Doc On-line, n. 16, 2014. p. 158 - 178. Disponível em: http://doc.ubi.pt/16/artigos16_3.pdf. Acesso em: 20 abr. 2020.

MELO, C. T. V. O Documentário como Gênero Audiovisual. In: Congresso Brasileiro de Ciências da Comunicação, 25, 2002, Salvador. Anais..., São Paulo: Intercom, 2002. v. 1.

NICHOLS, B. Introdução ao documentário. Trad. Mônica Sanddy Martins, 6 ed. Campinas, SP: Papirus, 2016.

ROJO, R. H. R. Letramentos: práticas de letramento em diferentes contextos. In: Letramentos múltiplos, escola e inclusão social. 1ạ. ed. São Paulo: Parábola Editorial, 2009.

SALLES, J. M. 3 questões sobre o documentário. Folha de São Paulo. São Paulo, 2001. Disponível em: http://www1.folha.uol.com.br/fsp/mais/fs0403200102.htm. Acesso em: 20 abr. 2020.

SILVINO, F. F. Letramento Visual. Texto Livre, v. 7, n. 1, 2014, p. 170. Disponível em: http://periodicos.letras.ufmg.br/index.php/textolivre. Acesso em: 20 abr. 2020.

SOBRAL, A. Do dialogismo ao gênero: as bases do pensamento do círculo de Bakhtin. Campinas, São Paulo: Mercado de Letras, 2009.

STREET, B. V. Abordagens alternativas ao letramento e desenvolvimento. Teleconferência: UNESCO Brasil, “Letramento e Diversidade”. King's College, Londres, 2003.

SWALES, J. Genre analysis: Engish in academic and research settings. Cambridge: Cambridge University Press, 1990. 
VIANNA, H. Manifesto de Hermano Vianna. Revista Raiz, 2007. Disponível em:

http://thacker.diraol.eng.br/mirrors/www.cultura.gov.br/site/2007/01/02/manifesto-dehermano-entrevista-com-hermano-vianna/. Acesso em: 20 abr. 2020.

Recebido em 31 de janeiro de 2020.

Aceito em 10 de abril de 2020.

${ }^{1}$ Grifos do autor. 